\title{
Training Future Health Providers to Care for the Underserved: A Pilot Interprofessional Experience
}

\author{
Memoona Hasnain ${ }^{1}$, Michael J. Koronkowski², Diane M. Kondratowicz' ${ }^{1}$, Kristen L. Goliak ${ }^{2}$ \\ ${ }^{1}$ Department of Family Medicine, College of Medicine, University of Illinois at Chicago, USA \\ ${ }^{2}$ Department of Pharmacy Practice, College of Pharmacy, University of Illinois at Chicago, USA
}

\begin{abstract}
Introduction: Interprofessional teamwork is essential for effective delivery of health care to all patients, particularly the vulnerable and underserved. This brief communication describes a pilot interprofessional learning experience designed to introduce medicine and pharmacy students to critical health issues affecting at-risk, vulnerable patients and helping students learn the value of functioning effectively in interprofessional teams. Methods: With reflective practice as an overarching principle, readings, writing assignments, a community-based immersion experience, discussion seminars, and presentations were organized to cultivate students' insights into key issues impacting the health and well-being of vulnerable patients. A written program evaluation form was used to gather students' feedback about this learning experience. Results: Participating students evaluated this learning experience positively. Both quantitative and qualitative input indicated the usefulness of this learning experience in stimulating learners' thinking and helping them learn to work collaboratively with peers from another discipline to understand and address health issues for at-risk, vulnerable patients within their community. Discussion: This pilot educational activity helped medicine and pharmacy students learn the value of functioning effectively in interprofessional teams. Given the importance of interprofessional teamwork and the increasing need to respond to the health needs of underserved populations, integrating interprofessional learning experiences in health professions training is highly relevant, feasible, and critically needed.
\end{abstract}

Keywords: Interprofessional care, interprofessional education, interprofessional learning, underserved populations

\section{Introduction}

Interprofessional teamwork is essential for effective delivery of health care to all patients, especially the vulnerable and underserved. Interprofessional education builds collaborative linkages among health care professions and communities, thereby, facilitating the provision of patient-centered care. ${ }^{[1,2]}$ This paper describes a pilot interprofessional learning initiative at an academic medical center in Midwest USA, which builds on the prior work of the institution's Colleges of Medicine and Pharmacy. ${ }^{[3,4]}$

\begin{tabular}{|l|l|}
\hline \multicolumn{2}{|c|}{ Access this article online } \\
\hline $\begin{array}{l}\text { Quick Response Code: } \\
\text { ⿴囗十 }\end{array}$ & $\begin{array}{l}\text { Website: } \\
\text { www.educationforhealth.net }\end{array}$ \\
\cline { 2 - 2 } & \\
\hline
\end{tabular}

\section{Methods}

A three-week intensive course was developed and offered as an interprofessional learning experience for medicine and pharmacy students. For Medicine, the course was a "selective" [short course] for third-year medical students rotating through the Family Medicine Clerkship. All students rotating through the clerkship are required to participate in at least four selectives chosen from a menu offered to them at the beginning of the clerkship. Placement is made on a first-come basis. For Pharmacy, the course was a module embedded in the Advanced Pharmacy Practice Experience [a required component of training for all fourth-year pharmacy students]. Participation for this pilot experience was limited to 12 students (six from each discipline). The students who participated were from a single academic year. All 12 students who were enrolled completed the course [100\% participation rate].

\section{Address for correspondence:}

Prof. M Hasnain, Director of Research \& Director, Patient-centered Medicine Scholars Program, Department of Family Medicine (MC 663), College of Medicine, University of Illinois at Chicago, 1919 W. Taylor Street, Chicago, IL 60612-7309, USA. E-mail: memoona@uic.edu 
[Downloaded free from http://www.educationforhealth.net on Thursday, January 23, 2014, IP: 131.193.153.34] || Click here to download free Android application for journal

\section{Learning objectives}

The course was designed to enable students to:

1. Practice reflective inquiry;

2. Apply an evidence-based, patient-centered, interprofessional team perspective to address health issues impacting HIV/ AIDS patients;

3. Relate experiences to the larger regional and national contexts;

4. Be effective members of interprofessional teams.

\section{Instructional strategies were organized around}

1. Critically appraising published literature on priority health issues affecting HIV/AIDS patients;

2. Using a patient-centered and shared-decision making approach, working in interprofessional dyads, to develop management plans for patients; and

3. Analyzing effective programmatic and policy strategies related to care provision for vulnerable and underserved HIV/AIDS patients.

Week 1 - Introductory seminar and first community site visit: [four hours] Medicine and Pharmacy faculty introduced the course, provided background about health disparities, established interprofessional student dyads, and accompanied students to the community agency. Each student was provided a "Resource Folder" with program materials and readings. At the community site, students met the agency staff, learned about services and met with patients for HIV testing. Each dyad participated in an initial intake interview with one patient, discussed with the patient his/her risks for HIV/AIDS, personal health status, social history, patient's concerns and questions, and observed HIV testing procedures. The goal was to prioritize a key health or quality of life issue of primary concern to the patient.

Week 2 - Independent and dyad work: [time duration variable for students] Students worked independently to research topics of relevance to the health management of their respective patients and the HIV/AIDS population at large. Student dyads met to develop an integrated health management plan to share with their patients and the community agency staff for follow-up care. The plan included system navigation for addressing identified health and well-being issues. As appropriate, students developed care plan recommendations regarding promoting physical fitness, nutrition, preventive health screenings, vaccinations, healthy choices, avoiding risky behaviors, and identifying pertinent community resources to address health care access issues.

Week 3 - Concluding seminar: [four hours] Student dyads presented their respective patient's case and management plan, and discussed effective programmatic and policy approaches to address issues for HIV/AIDS patients, including identifying resources and strategies to empower vulnerable patients to assume some measure of involvement in and responsibility for their health and well-being. The reflection and presentation had a special emphasis on integrating each discipline's perspective. A guide preparing students for this concluding seminar was provided to students at the beginning of the course (see Appendix). Students also shared their reflections about working collaboratively with interprofessional colleagues.

\section{Program evaluation}

Students completed a written program evaluation with seven quantitative ratings and two open-ended questions. The evaluation questions were developed by course faculty. Descriptive statistics were computed for the quantitative data. Content analysis methodology ${ }^{[5]}$ was used to code and develop themes from the qualitative data. Two raters [ $\mathrm{MH}$ and $\mathrm{MJK}$ ] performed the qualitative analysis. After creating initial themes individually, any discrepancies were discussed and resolved mutually. The University of Illinois at Chicago's Institutional Review Board (IRB) reviewed and approved this educational research.

\section{Results}

Overall, students positively rated the program's impacts on their learning [Table 1]. Of the quantitative ratings, the highest mean was 8.28 (out of 10) for: "This program stimulated my thinking, made me look at things in new ways"; the lowest mean was 6.16 (out of 10) for: "This program incorporated evidencebased information".

Responses to open-ended questions were classified in six

\section{Table 1: Quantitative ratings of student-reported program impacts}

\begin{tabular}{|c|c|c|c|}
\hline Items* & $\mathrm{N}$ & Mean & Standard deviation \\
\hline This program was learner-centered, that is, it actively engaged me in addressing questions/issues that were important to me & 12 & 7.8 & 2.01 \\
\hline This program stimulated my thinking, made me look at things in new ways & 12 & 8.28 & 2.14 \\
\hline This program helped me learn new knowledge and skills & 12 & 7.55 & 2.3 \\
\hline This program incorporated evidence-based information & 12 & 6.16 & 2.83 \\
\hline This program will influence my practice behavior with patients & 12 & 7.85 & 2.48 \\
\hline This program will influence my practice behavior with colleagues from other professions & 12 & 7.8 & 2.77 \\
\hline Overall educational value of the program & 12 & 8 & 1.56 \\
\hline
\end{tabular}


[Downloaded free from http://www.educationforhealth.net on Thursday, January 23, 2014, IP: 131.193.153.34] || Click here to download free Android application for journal

Hasnain, et al:: Interprofessional Education for Health Professions Students

Table 2: Major themes and frequency of open-ended responses

\begin{tabular}{lcc} 
& $\begin{array}{c}\text { What is the most important impact this } \\
\text { program had on you } \\
\text { (10 comments) }\end{array}$ & $\begin{array}{c}\text { What were the most effective aspects } \\
\text { of the program } \\
(19 \text { comments) }\end{array}$ \\
\hline Themes & Frequency (\%) \\
\hline Learning to working with underserved patients & $4(40 \%)$ & 0 \\
Learning to work with other disciplines & $2(20 \%)$ & $4(21 \%)$ \\
Learning about patient-centered care & $1(10 \%)$ & 0 \\
Identification and utilization of resources to help patients & $2(20 \%)$ & $2(10.5 \%)$ \\
Direct immersion experience at community agency & $1(10 \%)$ & $11(58 \%)$ \\
Course format - instructional design and reflection & 0 & $2(20 \%)$ \\
\hline
\end{tabular}

major themes. Students noted as among the "most effective" and "important impacts" of the course: visit to the agency; immersion in the community setting; interaction with patients; exposure to the issues and challenges faced by vulnerable patients; learning about patient-centered care and community resources; and, the opportunity to work collaboratively with peers from another discipline. The frequency and proportion of open-ended comments by theme is provided in Table 2 .

\section{Selected student comments}

"Interacting with an HIV patient with previous history of substance abuse and addiction opened my eyes to a different category of people who are in need of health care."

"...learning about the effectiveness of non-conventional outreach efforts to improve patient/community health."

"...reminder that there are so many aspects of patient care, and many different health care professionals who need to come together and collaborate."

\section{Discussion}

This pilot learning experience indicates the utility of tapping into the underutilized area of interprofessional education for health professions students. With reflective practice as an overarching principle, readings, individual assignments, a community-based immersion experience, discussion seminars, and presentations were organized to cultivate students' insights into key issues affecting the health and well-being of vulnerable patients. Overall, the experience was evaluated positively by students. Both quantitative ratings and openended student feedback indicate that students found this learning experience highly beneficial.

The variability in quantitative ratings from participants, particularly the lowest ratings given the item related to incorporating evidence-based information, gives us reason to pause to think why this was so. Since the bulk of the experience was on actual community immersion and student reflection, students may have considered this learning format to be less evidence-based than the traditional class-room or hospital-based learning experiences that they are used to. The range of ratings ascribed by students to various aspects of the learning experience certainly provides insight for further educational research as well as modifications to future iterations of this endeavor.

Given the importance of interprofessional teamwork and the increasing need to respond to the health needs of underserved populations, integrating interprofessional learning experiences in health professions training is highly relevant, feasible, and critically needed in health professions education. Although initial work in this area indicates positive influences of interprofessional learning experiences on participants' attitudes, much needs to be done in establishing the effect on patient outcomes. ${ }^{[6]}$

Limitations of our project include the small sample of participating students; the brief duration of the learning experience; and the limited scope of the program evaluation. Despite these limitations, we believe that these initial program evaluation findings provide rationale for moving forward with this line of teaching and developing integrated educational programs that involve students from a variety of health professions.

\section{Conclusions}

Medical education in the United States is at a historical crossroads. Since the publication of Flexner's revolutionary 1910 report, the health care system has radically changed, calling for an equally radical change in the way we teach future physicians and other health professions students. A substantial body of evidence underscores the importance of inter-professional education and community-based immersion experiences as instructional settings. ${ }^{[7]}$ This brief educational activity allowed the authors to create a rich and meaningful learning experience for students, not only to understand the needs of underserved and vulnerable patients, but also to cultivate the values and principles of working effectively in interprofessional teams. Further work along this line is needed to create similar educational experiences aimed at helping future health providers acquire the attitudes, values, and competencies necessary to meet the health needs of additional at-risk, vulnerable populations. Such 
[Downloaded free from http://www.educationforhealth.net on Thursday, January 23, 2014, IP: 131.193.153.34] || Click here to download free Android application for journal

interprofessional educational activities have tremendous potential for replication across other settings, particularly in low-income communities, locally and globally.

\section{Acknowledgements}

Funding for this interprofessional educational project was provided [in part] by the Association for Prevention Teaching and Research (APTR). The authors are thankful to the anonymous reviewers for their helpful feedback on an earlier version of this paper.

\section{References}

1. Reeves S, Russell A, Zwarenstein M, Kenaszchuk C, Conn LG, Doran D, et al. Structuring communication relationships for interprofessional teamwork (SCRIPT): A Canadian initiative aimed at improving patient-centered care. J Interprof Care 2007;21:111-4.

2. Dacey M, Murphy JI, Anderson DC, McCloskey WW. An interprofessional service-learning course: Uniting students across educational levels and promoting patient-centered care. J Nurs Educ 2010;49:696-9.

3. Hasnain M, Connell KJ, Kondratowicz DM, Hyderi AA, Dykens JA, Oyola S, et al. Training Future Physicians to Care for the
Underserved. $43^{\text {rd }}$ Annual Spring Conference of the Society of Teachers of Family Medicine, Vancouver, British Columbia, Canada. April 2010.

4. Smith M, Koronkowski M, Petersen N. Enhancing student learning through integrating community-based geriatric educational outreach into ambulatory care advanced practice experiential training. Am J Pharm Educ 2004;68:1-12.

5. Duncan DF. Content analysis in health education research: An introduction to purposes and methods. Health Educ 1989;20:27-31.

6. Reeves S, Zwarenstein M, Goldman J, Barr H, Freeth D, Koppel I, et al. The effectiveness of interprofessional education: Key findings from a new systematic review. J Interprof Care 2010;24:230-41.

7. Macy J Jr. Foundation. Revisiting the Medical School Education Mission at a time of expansion. 2009. Available from: http://www. macyfoundation.org/docs/macy_pubs/Macy_MedSchoolMission_ proceedings_06-09.pdf [Last accessed on 2013 Jan 28].

\footnotetext{
How to cite this article: Hasnain M, Koronkowski MJ, Kondratowicz DM, Goliak KL. Training Future Health Providers to Care for the Underserved: A Pilot Interprofessional Experience. Educ Health 2012;25:204-7.

Financial support: [In part] by the Association for Prevention Teaching and Research (APTR). This work was presented in January 2010 at the $36^{\text {th }}$ Annual STFM Predoctoral Education Conference, Jacksonville, FL. Conflict of Interest: No
}

\section{Appendix}

\section{Interprofessional Reflective Practice: \\ Addressing the Health Needs of Vulnerable Patient \\ Guide for Week \#3 \\ Reflective Responses and Presentation}

1. (Individual) Write a brief paragraph describing the role community service advocacy groups, such as the participating community agency we visited, play in addressing the specific health needs of the clients served.

2. (Individual) Utilize reflection to describe your thoughts, feelings, observations and interactions with the client you encountered.

3. (Team) Develop a brief reflective paper for presentation and discussion

a. Describe the patient encounter emphasizing their needs, health concerns, barriers to health care access.

b. Develop a two pronged (the participating community agency, Client) plan and possible solutions to perceived needs and barriers to health care access.

4 (Team) Comment on the lessons learned from this experience, focusing on the interprofessional student team community learning experience.

\section{Expectations:}

Each Team will have 30 minutes, including discussion, to present. Audio visual aids, if needed, can be provided. Portions of the students' papers that are relevant to helping the patient or site directly will be shared with the participating community agency.

Thank you for your participation in this program, the efforts to compile your reflections, as well as your thoughtful responses to the site and client needs assessment plan. We hope that you have had a meaningful experience. 